\title{
DESAIN STRATEGI PENGEMBANGAN USAHA DENGAN METODE FUZZY- SWOT DALAM ANCAMAN PANDEMI COVID-19 (STUDI KASUS PADA BENGKEL ANUGERAH POKA)
}

\author{
Alfredo Tutuhatunewa ${ }^{1 *}$, Lidya Pesulima ${ }^{2}$ \\ ${ }^{1}$ Jurusan Teknik Industri Universitas Pattimura, Ambon 97233 \\ *Email: alfredo.tutuhatunewa@fatek.unpatti.ac.id \\ 2Jurusan Teknik Industri Universitas Pattimura, Ambon 97233 \\ Email: lidyapesu5@gmail.com
}

\begin{abstract}
Abstrak. Kondisi pandemi covid-19 menyebabkan bengkel Anugerah Poka mengalami penurunan jumlah pelanggan. Untuk tetap mempertahankan eksistensinya, bengkel Anugerah Poka perlu melakukan desain strategi, dengan mencari kesesuaian kekuatankekuatan internal dan eksternalnya. Penelitian ini bertujuan untuk mendesain strategi pengembangan usaha Bengkel Anugerah Poka dengan metode Fuzzy-SWOT. Pendekatan fuzzy-SWOT dipakai untuk menghilangkan berbagai kelemahan struktural metode SWOT. Hasil penelitian menunjukkan bahwa strategi yang harus dikembangkan Bengkel Anugerah Poka adalah terus menjaga harga tetap rendah dibanding pesaing lain. Strategi selanjutnya adalah ekspansi jasa dalam kondisi pandemi Covid-19, agar terus meningkatkan pangsa pasar yang ada. Strategi berikut adalah dengan meningkatkan layanan, sambil terus menjaga harga tetap rendah dan memberikan layanan prima kepada pelanggan.
\end{abstract}

Kata kunci: Bengkel, Covid-19, SWOT, Fuzzy-SWOT

\begin{abstract}
The Covid-19 pandemic has caused the Anugerah Poka workshop to experience a decrease in the number of customers. To maintain its existence, the Anugerah Poka workshop needs to design a strategy, by looking for the suitability of its internal and external strengths. This study aims to design a business development strategy for the Anugerah Poka Workshop using the Fuzzy-SWOT method. The fuzzy-SWOT approach is used to eliminate various structural weaknesses of the SWOT method. The results showed that the strategy that the Anugerah Poka Workshop had to develop was to keep prices low compared to other competitors. The next strategy is the expansion of services in the conditions of the Covid-19 pandemic, in order to continue to increase the existing market share. The following strategy is to improve service while continuing to keep prices low and provide excellent service to customers.
\end{abstract}

Keywords: Workshop, Covid-19, SWOT, Fuzzy-SWOT

\section{PENDAHULUAN}

Bengkel merupakan suatu usaha jenis wirausaha kecil dan menengah yang bergerak dalam bidang jasa pelayanan perbaikan, baik itu sepeda motor atau mobil [1]. Salah satu bengkel yang ada di desa Poka, Kota Ambon, adalah Bengkel Anugerah Poka. Bengkel ini dibangun pada tahun 2010 oleh Jason M. S. Pesulima dengan karyawan 4 berjumlah orang. Bengkel Anugerah Poka adalah bengkel yang menawarkan layanan tambal ban, ganti oli dan perbaikan alat kendaraan, baik sepeda motor maupun mobil. Selain itu, Bengkel Anugerah Poka juga menjual beberapa produk untuk menunjang pelayanan di bengkel tersebut, misalnya produk ban Aspira, baik ban dalam maupun ban luar serta pelumas untuk motor. Untuk menunjang kemampuannya melayani konsumen, Bengkel ini memiliki peralatan yang cukup lengkap. 
Saat ini, terdapat kurang lebih 6 buah usaha bengkel di desa Poka dengan berbagai jenis pelayanan yang ditawarkan, misalnya layanan tambal ban, ganti oli, perbaikan alat kendaraan, reset injeksi, dan pengaturan rem motor. Persaingan usaha kecil dan menengah, seperti bengkel menjadi semakin kompetitif, dengan penawaran berbagai jenis layanan, serta ditunjang dengan penjualan berbagai merk produk yang variatif dengan harga yang bersaing. Hal ini mengharuskan sebuah bengkel untuk mampu mengatur strategi sehingga bengkel tetap bertahan dalam persaingan dengan bengkel-bengkel lainnya. Setiap pihak akan melakukan perencanaan strategi agar dapat membantu usaha agar dapat melihat secara objektif kondisi-kondisi internal dan eksternal yang ada.

Kondisi pandemi covid-19 menyebabkan bengkel Anugerah Poka mengalami penurunan jumlah pelanggan. Jika sebelumnya jumlah pelanggan dalam sehari dapat mencapai kurang lebih 50 konsumen, setelah adanya pelaksanaan PSBB oleh pemerintah yang dikarenakan pandemi covid-19, jumlah pelanggan dalam sehari hanya kurang lebih 30 konsumen. Berkurangnya jumlah pelanggan dapat menjadi semakin parah jika dibiarkan, sebab ketatnya persaingan bengkel yang berada di daerah poka mendorong setiap pesaing untuk mengembangkan strategi masing-masing agar mendapat banyak pelanggan.

Untuk tetap mempertahankan eksistensinya, bengkel Anugerah Poka perlu melakukan desain strategi, dengan mencari kesesuaian kekuatankekuatan internal dan eksternalnya. Bengkel Anugerah Poka juga mengetahui bahwa pentingnya memperoleh keunggulan bersaing dan memiliki produk yang sesuai dengan kebutuhan konsumen dengan dukungan optimal dari sumber daya yang ada. Oleh karena itu Analisis SWOT dapat dilakukan oleh Bengkel Anugerah Poka untuk mengembangkan usahanya dalam berbagai perubahan atau masalah lingkungan yang terjadi, terutama dalam ancaman pandemi covid-19 yang sedang terjadi sekarang ini. Integrasi logika fuzzy digunakan untuk menghilangkan faktor ketidakpastian yang sering muncul dalam analisis SWOT.

Analisis SWOT adalah alat perencanaan strategis yang banyak digunakan dalam proses pengambilan keputusan [2]. Analisis SWOT memberikan informasi yang bermanfaat untuk mengidentifikasi faktor-faktor kunci internal dan eksternal yang penting untuk mencapai tujuan yang dimaksud. Dalam analisis SWOT, kekuatan atau kelemahan diklasifikasikan sebagai parameter internal sedangkan peluang dan ancaman diklasifikasikan sebagai parameter situasional eksternal [3], [4]. Analisis SWOT telah membantu dalam banyak industri seperti bisnis [5], [6], pendidikan [7], layanan kesehatan [8], dan perencanaan tata guna lahan dan perkotaan [9].

SWOT adalah alat manajemen untuk merumuskan rencana aksi strategis [10]. SWOT merupakan akronim untuk strengths, weaknesses, opportunities and threats. Analisis SWOT melibatkan proses penentuan tujuan dari usaha bisnis atau proyek dan mengidentifikasi faktorfaktor internal dan eksternal yang menguntungkan dan tidak menguntungkan untuk mencapai tujuan itu [10]. SWOT memaksimalkan kekuatan dan peluang, dan meminimalkan ancaman dan kelemahan. Dengan kata lain, Analisis SWOT mengubah kelemahan menjadi kekuatan, dan ancaman menjadi peluang [11].

Teknik ini dikreditkan ke Albert Humphrey, yang memimpin proyek penelitian di Universitas Stanford pada 1960-an dan 1970-an menggunakan data dari perusahaan-perusahaan Fortune 500. Setiap program, termasuk proses operasional, rencana manajemen, dan karakteristik pengembangan, memiliki kekuatan dan kelemahan, peluang dan ancaman.

Dalam analisis SWOT, sumber daya yang tersedia dan potensi pemanfaatannya dipelajari dari sudut pandang keberlanjutan ekonomi, ekologi dan sosial. Namun, tujuan utama dalam proses perencanaan adalah untuk mendapatkan dukungan keputusan yang akan digunakan dalam pemilihan strategi yang harus diikuti [11]. Dalam studi decisiontheoretic, keputusan dianggap sebagai pilihan antara dua atau lebih tindakan alternatif. Secara umum, pembuat keputusan rasional memilih alternatif yang memaksimalkan utilitas, ditentukan berdasarkan informasi yang tersedia pada alternatif keputusan. Dalam mendukung keputusan, informasi dihasilkan tentang situasi keputusan, dan tentang pilihan tindakan alternatif dan konsekuensinya. Model keputusan yang lengkap merupakan dasar untuk dukungan keputusan. Alternatif yang tersedia, informasi tentang konsekuensi yang terkait dengan alternatif ini dan preferensi di antara konsekuensi ini adalah tiga kriteria yang harus dipertimbangkan dalam pengambilan keputusan [12]. Setiap aspek dari informasi harus sehat sehingga alternatif terbaik dapat dipilih. SWOT dapat digunakan untuk analisis lingkungan internal dan eksternal untuk mencapai pendekatan sistematis dan dukungan untuk pengambilan keputusan dan, jika digunakan dengan benar, dapat memberikan dasar yang baik untuk perumusan strategi yang sukses. Dengan kata lain, analisis SWOT akan 
memberikan: kerangka kerja untuk menganalisis situasi dan mengembangkan strategi dan taktik yang sesuai; dasar untuk menilai kapabilitas dan kompetensi inti; dan bukti untuk dan kunci untuk berubah dan sukses; dan stimulus untuk berpartisipasi dalam pengalaman kelompok [13].

Meskipun analisis SWOT menonjol karena kesederhanaan dan nilainya dalam memusatkan perhatian pada isu-isu utama, akan tetapi metode ini memiliki keterbatasan - misalnya klasifikasi item yang tidak jelas sebagai kekuatan, kelemahan, peluang atau ancaman, atau subjektivitas berlebihan dalam pembuatan tema karena bias penyusun [14].

Analisis SWOT masih memiliki masalah struktural. Masalah yang paling penting adalah kurangnya pertimbangan terhadap faktor-faktor yang tidak pasti, kurangnya prioritas faktor dan strategi, dan terlalu banyak strategi yang dapat diekstraksi [15]. Dalam banyak situasi, tidak mungkin untuk membedakan faktor-faktor dengan jelas, apakah itu peluang atau ancaman. Misalnya, tidak memiliki pesaing yang kuat di pasar adalah peluang (untuk mengendalikan pasar), dan pada saat yang sama mungkin juga menjadi ancaman (karena dapat menyebabkan perusahaan tidak bertindak dan depresi). Kelemahan ini diatasi dengan penggunaan prinsip logika fuzzy. Logika fuzzy telah diintegrasikan dengan analisis SWOT untuk mengatasi ketidakjelasan dan ketidaktepatan pemikiran manusia [10].

Meskipun merupakan aplikasi yang banyak dipakai, metode SWOT juga memiliki sejumlah masalah [16], tetapi yang paling penting adalah sebagai berikut [15]:

- Biasanya hanya pemeriksaan kualitatif faktor lingkungan yang dipertimbangkan [17];

- Tidak ada prioritas untuk berbagai faktor dan strategi;

- Jika jumlah faktor lebih banyak, jumlah strategi yang diadopsi akan meningkat secara eksponensial (misalnya jika jumlah setiap set faktor S, W, O, T sama dengan 5, jumlah yang dihasilkan dari strategi gabungan akan ada sekitar 100 yang akan membuat pemilihan strategi yang tepat sangat sulit);

- Tidak mempertimbangkan ketidakjelasan faktor.

Penerapan logika fuzzy untuk menyelesaikan masalah struktural SWOT, seperti kurangnya mempertimbangkan faktor ketidakpastian dan faktor dua sisi dan kurangnya prioritas dikemukakan oleh Ghazinoory et al. [15]. Beberapa penggunaan integrasi Fuzzy dengan SWOT telah dilaporkan pada penelitian sebelumnya [18]-[21].
Logika fuzzy merupakan salah satu komponen pembentuk soft computing [22]. Logika fuzzy pertama kali diperkenalkan pada tahun 1965oleh Prof. Lotfi A. Zadeh, seorang peneliti di Universitas California di Barkley dalam bidang ilmu komputer. Professor Zadeh beranggapan bahwa logika benar - salahtidak dapat mewakili setiap pemikiran manusia.Kemudian, dikembangkanlah logika fuzzy yang dapat mempresentasikan setiap keadaan atau mewakili pemikiran manusia. Perbedaan antara logika tegasdan logika fuzzy terletak pada keanggotaan elemen dalam suatu himpunan. Jika dalam logika tegas suatu elemen mempunyai dua pilihan yaitu terdapat dalam himpunan atau bernilai 1 yang berarti benar dan tidak pada himpunan atau bernilai 0 yang berarti salah. Sedangkan dalam logika fuzzy, keanggotaan elemen berada di interval $[0,1]$. Dasar logika fuzzy adalah teori himpunan fuzzy. Pada teori himpunan fuzzy, peranan derajat keanggotaan sebagai penentu keberadaan elemen dalam suatu himpunan sangatlah penting. Nilai keanggotaan atau derajat keanggotaan atau membership function menjadi ciri utama dari penalaran dengan logika fuzzy tersebut.

Logika fuzzy menjadi alternatif dari berbagai sistem yang ada dalam pengambilan keputusan karena logika fuzzy mempunyai kelebihan sebagai berikut [23]:

a. Logika fuzzy memiliki konsep yang sangat sederhana sehingga mudah untuk dimengerti.

b. Logika fuzzy sangat fleksibel, artinya mampu beradaptasi dengan perubahan-perubahan dan ketidakpastian.

c. Logika fuzzy memiliki toleransi terhadap data yang tidak tepat.

d. Logika fuzzy mampu mensistemkan fungsifungsi non-linier yang sangat kompleks.

e. Logika fuzzy dapat mengaplikasikan pengalaman atau pengetahuan dari para pakar.

f. Logika fuzzy dapat bekerjasama dengan teknik-teknik kendali secara konvensional.

g. Logika fuzzy didasarkan pada bahasa seharihari sehingga mudah dimengerti.

Logika fuzzy memiliki beberapa komponen yang harus dipahami seperti himpunan fuzzy, fungsi keanggotaan, operator pada himpunan fuzzy, inferensi fuzzy dan defuzzifikasi.

\section{BAHAN DAN METODE}

\subsection{Prosedur Penelitian}

Survei lapangan merupakan proses awal penelitian, yang dilakukan untuk mendapat gambaran awal mengenai permasalahan yang dikaji, yaitu kondisi Bengkel Anugerah Poka. Selain itu, juga dilakukan pengamatan terhadap 
lingkungan sekitar, bengkel-bengkel lain yang merupakan pesaing, serta kondisi lain yang mungkin penting untuk pelaksanaan penelitian guna menjawab tujuan penelitian.

Studi literatur digunakan untuk mengumpulkan dan mendapat gambaran utuh mengenai penerapan metode SWOT dan integrasinya dengan metode Fuzzy untuk mengurangi ketidakpastian yang dihadapi, yang diperoleh dari artikel dan uraian ahli sebelumnya yang telah dipublikasi pada jurnal-jurnal internasional dan nasional yang relevan, serta berbagai laporan penelitian yang telah dipublikasikan sebelumnya.

Pada tahap selanjutnya, alat yang dibutuhkan bagi pengumpulan data, berupa kuesioner dan lembar pertanyaan wawancara disiapkan. Setelah itu dilakukan penggandaan untuk disebar kepada pemilik bengkel, tenaga kerja dan konsumen.

\subsection{Algoritma untuk fuzzifying Matriks SWOT}

Algoritma untuk memperbaiki kekurangan dan masalah matriks SWOT melalui penggunaan set fuzzy [15].

\section{a. Penskalaan faktor-faktor}

Untuk setiap faktor internal, fungsi keanggotaan yang sesuai dikembangkan dalam kisaran -10 hingga +10 . Karena setiap faktor dapat menunjukkan makna dua sisi, maka bagian negatif menunjukkan kelemahan dan bagian positif dari fungsi keanggotaan fuzzy menandakan kekuatan. Pernyataan yang sama juga berlaku untuk faktor eksternal.

Dalam domain yang didefinisikan antara kelemahan paling intensif (-10) dan kekuatan paling intensif $(+10)$, setiap faktor dapat menentukan tingkat kepemilikannya pada masingmasing titik domain dan titik-titik dimana konsentrasi utamanya berada, menggunakan fuzzy yang tepat fungsi keanggotaan.

Jenis fungsi keanggotaan bersifat opsional tetapi untuk menyederhanakan perhitungan lokasi area pada tahap berikutnya, disarankan menggunakan fungsi keanggotaan segitiga. "Fungsi keanggotaan segitiga" dapat ditentukan oleh tiga parameter $\left(x^{p}, x^{m}, x^{o}\right)$ sebagai berikut [24]:

$$
\begin{aligned}
& y=\operatorname{segitiga}\left(x ; x^{p}, x^{m}, x^{o}\right) \\
& =\left\{\begin{array}{cc}
\left(x-x^{p}\right) /\left(x^{m}-x^{p}\right), x^{p} \leq x \leq x^{m} \\
\left(x^{o}-x\right) /\left(x^{0}-x^{m}\right), x^{m} \leq x \leq x^{o} \\
0, & x^{o} \leq x
\end{array}\right.
\end{aligned}
$$

Dimana, $x^{p}, x^{m}$ dan $x^{o}$ masing-masing disebut nilai pesimis, kemungkinan, dan optimis. Kita dapat membuat daftar faktor termasuk kekuatan, kelemahan, peluang dan ancaman. Perbedaan antara tahap ini dan SWOT yang biasa adalah bahwa untuk kasus ini, 3 pertanyaan harus diajukan untuk setiap faktor internal dari pembuat keputusan:

Nilai apa yang akan dialokasikan dalam kisaran 10 hingga +10 untuk pesimis $\left(x^{p}\right)$, kemungkinan $\left(x^{m}\right)$ dan situasi optimis $\left(x^{o}\right)$ untuk faktor internal (10 hingga 0 untuk intensitas kelemahan dan 0 hingga +10 atau intensitas kekuatan)? Sebaran yang sama dari -10 hingga +10 juga diasumsikan untuk faktor eksternal dengan pertanyaan yang sama dan fungsi keanggotaan segitiga akan diperoleh untuk setiap faktor.

Ketiga kondisi dalam Matriks fuzzy-SWOT ditunjukkan pada Gambar 1.

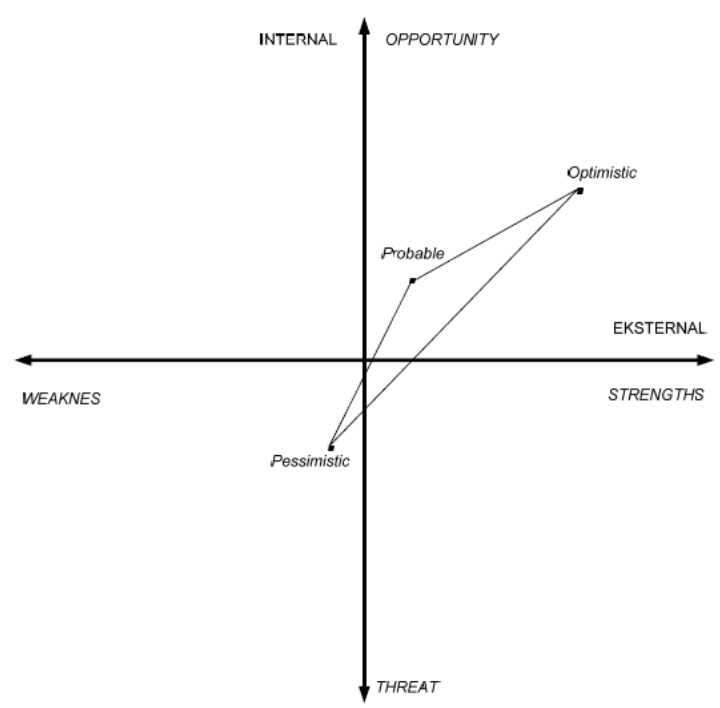

Gambar 1. Matrik Fuzzy-SWOT

\section{b. Agregasi fungsi keanggotaan faktor internal dan eksternal}

Untuk mengekstrak strategi berdasarkan faktorfaktor internal dan eksternal, perlu untuk menggabungkan fungsi keanggotaan faktor-faktor tersebut. Dalam hal ini, permukaan tiga dimensi didefinisikan berdasarkan pada fungsi keanggotaan faktor internal dan eksternal. Ini berlaku dengan menggunakan norma-t yang sesuai seperti operator min. Setiap titik permukaan ini dalam matriks SWOT berasal dari persimpangan fungsi keanggotaan faktor eksternal dan internal relatif.

\section{c. Evaluasi, penentuan prioritas dan penggalian strategi}

Dasar untuk evaluasi area yang dihasilkan dari tahap sebelumnya adalah jarak mereka dari sudutsudut matriks. Kriteria yang berbeda dapat ditentukan untuk jarak ini. 1) Min dari jarak Euclidean setiap titik sudut dari batas area, 2) min dari jarak setiap titik sudut dari pusat gravitasi area, 3) maks dari persentase area di setiap kuadran. Pemilihan masing-masing dari 3 kriteria ini tidak 
akan meninggalkan kesan pada prioritas, tetapi memperkenalkan mereka diperlukan untuk lebih memahami konsep jarak.

\subsection{Analisis Fuzzy SWOT}

Adapun proses langkah-langkah pembuatan analisa Fuzzy SWOT adalah sebagai berikut [25]:

1) Analisis data latar belakang dan visi produk atau perusahaan.

2) Tulis semua faktor eksternal produk atau perusahaan.

3) Tulis semua faktor internal produk atau perusahaan.

4) Susun faktor eksternal dan internal yang dominan dari segi aktivitas dan objektifitas.

5) Tentukan besaran nilai dari masing-masing faktor dengan ketiga kondisi pesimis (pessimistic), kemungkinan (probable) dan optimis (optimistic). Yang besaran nilainya berdasarkan skala -10 hingga +10 , dimana -10 menandakan posisi paling lemah untuk skala kelemahan atau ancaman dan skala +10 menandakan posisi paling kuat untuk skala kekuatan atau peluang. Nilai pesimis (pessimistic) $\leq$ kemungkinan (probable) $\leq$ optimis (optimistic). Kemudian Jumlahkan setiap variabel masing-masing responden dan dibagi jumlah responden, untuk menentukan nilai rata-rata setiap variabel.

6) Tentukan bobot dari masing-masing variabel internal dan eksternal dengan menggunakan skala 1-100. Yang nantinya akan dilakukan pembobotan kembali untuk total bobot dari variabel internal dan eksternal berjumlah 1 . Hal ini bisa dilakukan dengan melakukan diskusi kepada para ahli. Penelitian ini menggunakan nilai rata-rata dari tiga responden.

7) Hitung nilai rata-rata Fuzzy dari masing-masing faktor, berdasarkan perkalian masing-masing variabel dan bobotnya.

8) Hitung total nilai faktor internal (FIF) dan eksternal (FEF) dengan menjumlahkan nilai dari masing-masing variabel.

9) Tentukan posisi produk atau perusahaan dalam matrik Fuzzy SWOT berdasarkan total nilai faktor internal dan eksternal. Lokasi mayoritas koordinat menandakan daerah segitiga Fuzzy, yang nantinya satu daerah akan dimasukkan ke matrik Fuzzy SWOT.

\section{HASIL DAN PEMBAHASAN}

3.1. Visi, Misi, dan Tujuan dari Bengkel Anugerah Poka

\section{Visi}

"Menjadi usaha jasa bengkel yang terpercaya dan berkualitas, serta memberikan pelayanan terbaik kepada konsumen dan menjadi pusat penyediaan jasa service kendaraan yang unggul.”

\section{Misi}

1) Bengkel Anugerah Poka dapat memberikan pelayanan yang ramah, sopan, beretika dan terpercaya.

2) Bengkel Anugerah Poka memprioritaskan kepuasan konsumendengan caramenerapkan konsep A3 yaitu: Attitude (sikap), Attention (perhatian), dan Action (tindakan).

3) Adanya Profesionalitas tenaga kerja.

\section{Tujuan}

1) Memperoleh keuntungan dan pendapatan dari usaha mandiri yang dilakukan untuk mensejahterakan pemilik dan tenaga kerja.

2) Memperoleh kepercayaan yang optimal dari konsumen, sehingga dengan adanya kepercayaan yang diberikan diharapkan usaha bengkel dapat lebih berkembang.

\subsection{Identifikasi Faktor}

Faktor-faktor penting pengembangan strategi usaha bengkel diidentifikasi melalui wawancara dengan pihak bengkel, maupun pengguna jasa bengkel yang ditemui. Faktor-faktor tersebut adalah:

\section{Faktor internal:}

1. Bengkel memiliki peralatan yang memadai.

2. Bengkel memiliki tenaga kerja terampil dan berpengalaman.

3. Bengkel menyediakan produk perlengkapan bagi kendaraan.

4. Harga yang bersaing.

5. Bengkel tidak memiliki ruang tunggu yang memadai.

6. Bengkel belum memiliki layanan antar jemput kendaraan yang diservis.

7. Bengkel memiliki keterbatasan anggaran.

\section{Faktor eksternal:}

1. Peralatan memungkinkan untuk ekspansi layanan.

2. Penambahan jumlah kendaraan roda 2 menambah pangsa pasar sasaran.

3. Supplier yang mudah bekerja sama.

4. Pandemi COVID-19 yang masih terus mengancam.

5. Bengkel pesaing memiliki penampilan menarik.

6. Bengkel pesaing menawarkan layanan yang lebih lengkap.

\subsection{Matriks Faktor Strategi}


Faktor internal dan eksternal telah diidentifikasi, selanjutnya, fungsi keanggotaan ditentukan dengan menanyai orang yang memahami masalah perbengkelan, mengenai nilai $\mathrm{a}, \mathrm{b}$ dan $\mathrm{c}$ seperti yang ditunjukkan pada Tabel 1 dan 2. Nilai-nilai tersebut menunjukkan bilangan segitiga fuzzy (FTN) untuk menganalisis kekuatan, kelemahan, peluang, dan ancaman dari bengkel Anugerah Poka yang dipertimbangkan. Jumlah ini pertama kali dikumpulkan dengan istilah linguistik dari pendapat ahli dan kemudian ditransfer ke nilai kuantitatif FTN

Tabel 1 dan 2 menunjukkan nilai $\mathrm{FIF}=(0,714$, $1,857,3,143)$ dan $\mathrm{FEF}=(-3,833,-1,667,0,500)$. Berdasarkan faktor-faktor yang disebutkan di atas, matriks SWOT digambarkan sebagaimana ditunjukkan pada Tabel 3.

Tabel 1. Faktor Internal

\begin{tabular}{clccc}
\hline \multirow{2}{*}{ Kode } & \multirow{2}{*}{ Faktor } & \multicolumn{2}{c}{ Nilai } \\
\cline { 3 - 5 } & & $\mathrm{a}$ & $\mathrm{b}$ & $\mathrm{c}$ \\
\hline $\mathrm{I}_{1}$ & Bengkel memiliki peralatan yang memadai. & 7 & 9 \\
$\mathrm{I}_{2}$ & Harga yang bersaing. & 7 & 8 & 9 \\
$\mathrm{I}_{3}$ & Bengkel memiliki tenaga kerja terampil dan berpengalaman. & 6 & 7 & 9 \\
$\mathrm{I}_{4}$ & Bengkel menyediakan produk perlengkapan bagi kendaraan. & 5 & 6 & 7 \\
$\mathrm{I}_{6}$ & Bengkel tidak memiliki ruang tunggu yang memadai. & -8 & -7 & -6 \\
$\mathrm{I}_{7}$ & Bengkel belum memiliki layanan antar jemput kendaraan yang diservis. & -6 & -5 & -4 \\
$\mathrm{I}_{7}$ & Bengkel memiliki keterbatasan anggaran. & -6 & -4 & -2 \\
\hline & FIF & $\mathbf{0 , 7 1 4}$ & $\mathbf{1 , 8 5 7}$ & $\mathbf{3 , 1 4 3}$ \\
\hline
\end{tabular}

Tabel 2. Faktor Eksternal

\begin{tabular}{clccc}
\hline \multirow{2}{*}{ Kode } & \multicolumn{1}{c}{ Faktor } & \multicolumn{2}{c}{ Nilai } \\
\cline { 3 - 5 } & & $\mathrm{a}$ & $\mathrm{b}$ & $\mathrm{c}$ \\
\hline $\mathrm{E}_{1}$ & Peralatan memungkinkan untuk ekspansi layanan. & -2 & 1 & 4 \\
$\mathrm{E}_{2}$ & Penambahan jumlah kendaraan roda 2 menambah pangsa pasar sasaran. & -1 & 2 & 5 \\
$\mathrm{E}_{3}$ & Supplier yang mudah bekerja sama. & 1 & 3 & 5 \\
$\mathrm{E}_{4}$ & Pandemi COVID-19 yang masih terus mengancam. & -9 & -8 & -7 \\
$\mathrm{E}_{5}$ & Bengkel pesaing memiliki penampilan menarik. & -6 & -4 & -2 \\
$\mathrm{E}_{6}$ & Bengkel pesaing menawarkan layanan yang lebih lengkap. & -6 & -4 & -2 \\
\hline & FEF & $\mathbf{- 3 , 8 3 3}$ & $\mathbf{- 1 , 6 6 7}$ & $\mathbf{0 , 5 0 0}$ \\
\hline
\end{tabular}

Tabel 3. Matriks Kekuatan, Kelemahan, Peluang dan Ancaman (SWOT)

\begin{tabular}{|c|c|c|c|}
\hline & \multirow[b]{2}{*}{$\begin{array}{l}\text { SWOT } \\
\text { untuk } \\
\text { Bengkel }\end{array}$} & \multicolumn{2}{|l|}{ Faktor eksternal } \\
\hline & & $\begin{array}{l}\text { Peluang } \\
\text { - Peralatan yang dimiliki memungkinkan } \\
\text { bengkel melakukan ekspansi layanan. } \\
\text { - Penambahan jumlah kendaraan roda } 2 \\
\text { menambah pangsa pasar sasaran. } \\
\text { - Kerja sama dengan pemasok } \\
\text { memungkinkan penambahan jenis } \\
\text { produk yang dijual. }\end{array}$ & $\begin{array}{l}\text { Ancaman } \\
\text { - Pandemi COVID-19 yang } \\
\text { masih terus mengancam. } \\
\text { - Bengkel pesaing memiliki } \\
\text { penampilan menarik. } \\
\text { - Bengkel pesaing } \\
\text { menawarkan layanan yang } \\
\text { lebih lengkap. }\end{array}$ \\
\hline \multirow{2}{*}{ 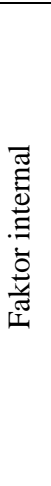 } & $\begin{array}{l}\text { Kekuatan } \\
\text { - Bengkel memiliki peralatan memadai. } \\
\text { - Harga yang bersaing. } \\
\text { - Bengkel memiliki tenaga kerja terampil } \\
\text { dan berpengalaman. } \\
\text { - Bengkel menyediakan produk } \\
\text { perlengkapan bagi kendaraan. } \\
\end{array}$ & Strategi SO & Strategi ST \\
\hline & $\begin{array}{l}\text { Kelemahan } \\
\text { - Bengkel tidak memiliki ruang tunggu } \\
\text { yang memadai. } \\
\text { - Bengkel belum memiliki layanan antar } \\
\text { jemput kendaraan yang diservis. } \\
\text { - Bengkel memiliki keterbatasan anggaran. }\end{array}$ & Strategi WO & Strategi WT \\
\hline
\end{tabular}


Tabel 4. Strategi Pengembangan Usaha Bengkel Anugerah Poka

\begin{tabular}{|c|c|c|c|}
\hline \multicolumn{4}{|c|}{ Faktor eksternal } \\
\hline & $\begin{array}{l}\text { SWOT } \\
\text { untuk } \\
\text { Bengkel }\end{array}$ & $\begin{array}{l}\text { Peluang } \\
\text { - Peralatan yang dimiliki } \\
\text { memungkinkan bengkel } \\
\text { melakukan ekspansi layanan. } \\
\text { - } \quad \text { Penambahan jumlah } \\
\text { kendaraan roda } 2 \text { menambah } \\
\text { pangsa pasar sasaran. } \\
\text { Kerja sama dengan pemasok } \\
\text { memungkinkan penambahan } \\
\text { jenis produk yang dijual. }\end{array}$ & 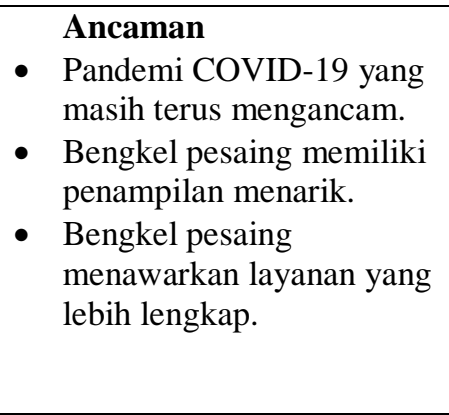 \\
\hline & $\begin{array}{l}\text { Kekuatan } \\
\text { - } \quad \text { Bengkel memiliki peralatan } \\
\text { yang memadai. } \\
\text { - Harga yang bersaing. } \\
\text { - } \quad \text { Bengkel memiliki tenaga kerja } \\
\text { terampil dan berpengalaman. } \\
\text { - Bengkel menyediakan produk } \\
\text { perlengkapan bagi kendaraan. }\end{array}$ & $\begin{array}{l}\text { - Menjaga kestabilan harga jual, } \\
\text { pengembangan usaha. }\end{array}$ & 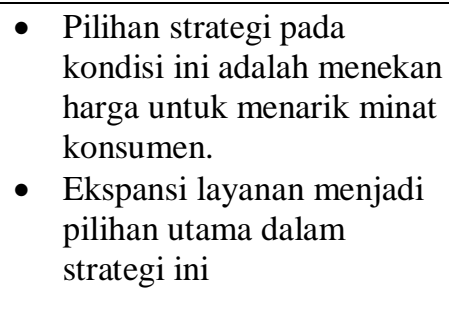 \\
\hline 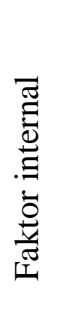 & $\begin{array}{l}\text { Kelemahan } \\
\text { - } \quad \text { Bengkel tidak memiliki ruang } \\
\text { tunggu yang memadai. } \\
\text { - Bengkel belum memiliki } \\
\text { layanan antar jemput kendaraan } \\
\text { yang diservis. } \\
\text { - Bengkel memiliki keterbatasan } \\
\text { anggaran. }\end{array}$ & $\begin{array}{l}\text { Pangsa pasar harus dapat } \\
\text { ditingkatkan dengan } \\
\text { perbaikan pelayanan terutama } \\
\text { fisik bengkel. }\end{array}$ & $\begin{array}{l}\text { Pengembangan dengan } \\
\text { layanan antar jemput } \\
\text { kendaraan bisa menjadi } \\
\text { solusi dalam kondisi } \\
\text { pandemi Covid-19 }\end{array}$ \\
\hline
\end{tabular}

\subsection{Agregasi}

Untuk mengekstrak strategi, setiap pasangan faktor internal dan eksternal harus dibandingkan satu per satu. Setiap pasangan faktor internal dan eksternal (setelah agregasi) ditempatkan dalam matriks SWOT fuzzy 3D. Fungsi Keanggotaan Agregat dapat diekstraksi dari penggabungan fungsi keanggotaan faktor internal dan eksternal. Gambar 2 menunjukkan bagaimana permukaan ini dibuat.

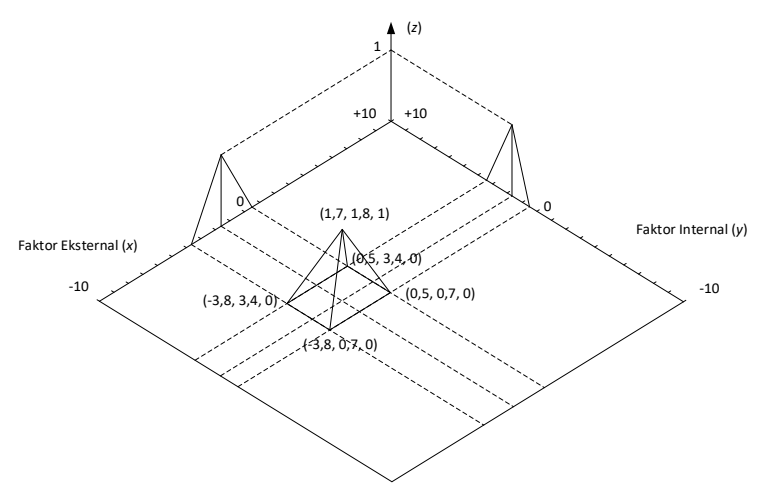

Gambar 2. Proses Agregasi

\subsection{Evaluasi dan Ekstraksi Strategi}

Untuk mengevaluasi pentingnya sepasang faktor internal/eksternal untuk ekstraksi strategi, perlu diketahui, dimana letak titik yang merupakan hasil agregasi. Semakin dekat titik ke sudut, semakin penting titik tersebut. Pada pendekatan fuzzy, faktor hasil penggabungan berupa himpunan titik-titik fuzzy (sebuah area fuzzy) bukan sebuah titik. Dengan menggunakan potongan yang tepat (1-potong, kita dapat memiliki area yang lebih kecil dan memudahkan evaluasi yang dilakukan.

Semakin besar $\alpha$, semakin banyak informasi tentang kasus tersebut diabaikan. Oleh karena itu, penentuan $\alpha$ harus dilakukan oleh pengambil keputusan akhir. Setiap nilai $\alpha$ dapat membuat area dalam matriks SWOT dan pertanyaannya adalah titik area mana yang harus diperhitungkan untuk menentukan kepentingan. Penentuan ini tergantung tentang pesimisme dan optimisme seorang pengambil keputusan, misalnya jika pengambil keputusan pesimis, ia akan memilih nilai minimum untuk faktor internal dan eksternal, sehingga titik yang dipilih akan lebih dekat ke sudut kiri matriks $(-10,-10)$ dan dalam kasus pembuat keputusan yang optimis, itu akan berada di sisi yang berlawanan.

Dari nilai FIF dan FEF, digambarkan tiga poin strategis dalam matriks Fuzzy SWOT, dimana Titik 1 dan 2 berada pada bidang KekuatanAncaman, sementara Titik 3 pada bidang Kekuatan-Peluang. 


\subsection{Pembahasan}

Berdasarkan hasil perhitungan sebelumnya, terdapat beberapa hal yang perlu menjadi perhatian, antara lain:

1. Terdapat 2 titik strategis yang berada pada bidang Kekuatan-Ancaman, yaitu titik A $(0,714,-3,833)$ dan titik B $(1,857,-1,667)$.

Bengkel Anugerah Poka berhadapan dengan kondisi pandemi Covid-19 yang menekan perkembangan usaha apapun saat ini. Meskipun sudah berlangsung 9 bulan, dan belum ada titik terang akan berakhirnya pandemi ini, Bengkel memiliki strategi untuk terus menjaga harga tetap rendah dibanding pesaing lain. Hal ini memang menurunkan tingkat keuntungan, tetapi memberikan peluang besar untuk merebut pelanggan dari pesaing karena harga yang lebih murah untuk jenis layanan yang sama. Selain itu, ekspansi jasa juga merupakan strategi yang harus dikembangkan dalam kondisi ini, untuk meningkatkan pangsa pasar yang ada.

2. Salah satu titik strategi berada pada bidang Kekuatan-Peluang, yaitu titik C $(3,143,0,500)$. Hal ini memudahkan bengkel Anugerah Poka untuk meningkatkan layanan yang diberikan, sambil terus menjaga harga tetap rendah dan memberikan layanan prima kepada pelanggan.

\section{KESIMPULAN}

Strategi yang harus dikembangkan Bengkel Anugerah Poka adalah terus menjaga harga tetap rendah dibanding pesaing lain. Hal ini memang menurunkan tingkat keuntungan, tetapi memberikan peluang besar untuk merebut pelanggan dari pesaing karena harga yang lebih murah untuk jenis layanan yang sama.Strategi berikut adalah ekspansi jasa dalam kondisi pandemi Covid-19, untuk terus meningkatkan pangsa pasar yang ada.Selain itu, strategi dengan meningkatkan layanan, sambil terus menjaga harga tetap rendah dan memberikan layanan prima kepada pelanggan.

Penelitian ini memiliki keterbatasan karena jumlah sampel yang sedikit, sehingga lemah dalam generalisasi hasil terhadap keseluruhan populasi. Penelitian lebih lanjut harus diarahkan untuk dilakukan dengan pengambilan sampel yang lebih besar. Selain itu, obyek penelitian memiliki banyak keterbatasan sumber daya. Kelemahan ini membuat metode yang digunakan mungkin tidak begitu tepat dalam memecahkan masalah yang dihadapi. Penelitian lanjutan seharusnya diarahkan untuk mengembangkan metode yang lebih sederhana untuk memecahkan masalah pengembangan strategi bagi usaha sejenis.

\section{UCAPAN TERIMA KASIH}

Penelitian ini terlaksana dengan dana PNBP Fakultas Teknik Universitas Pattimura tahun 2020. Untuk itu, penulis mengucapkan terima kasih kepada Pimpinan Fakultas Teknik Unpatti atas kesempatan menerima bantuan dana penelitian ini.

\section{DAFTAR PUSTAKA}

[1] J. Yoga, "Perancangan Sistem Inventory Spare Part Motor Pada CV. Surya Jaya Jepara," Skripsi, Universitas Dian Nuswantoro, 2013. Accessed: Jul. 23, 2020. [Online]. Available: http://eprints.dinus.ac.id/12680/

[2] J. Cui, A. Allan, and D. Lin, "SWOT analysis and development strategies for underground pedestrian systems," Tunnelling and Underground Space Technology, vol. 87, pp. 127-133, May 2019, doi: 10.1016/j.tust.2018.12.023.

[3] R. W. Griffin, Management, 10th ed. Mason, Ohio: South-Western Cengage Learning, 2009.

[4] N. Pahl and A. Richter, SWOT analysis idea, methodology and a practical approach . Munich.: GRIN Verlag, 2007.

[5] A. Paschalidou, M. Tsatiris, and K. Kitikidou, "Energy crops for biofuel production or for food? - SWOT analysis (case study: Greece)," Renewable Energy, vol. 93, pp. 636-647, Aug. 2016, doi: 10.1016/j.renene.2016.03.040.

[6] K. Zharan and J. C. Bongaerts, "Decisionmaking on the integration of renewable energy in the mining industry: A case studies analysis, a cost analysis and a SWOT analysis," Journal of Sustainable Mining, vol. 16, no. 4, pp. 162-170, Jan. 2017, doi: 10.1016/j.jsm.2017.11.004.

[7] S. Hlungwani, "Analysis of the current situation of nursing education in South Africa (SWOT)," International Journal of Nursing Sciences, vol. 4, no. 4, p. 348, Oct. 2017, doi: 10.1016/j.ijnss.2017.10.014.

[8] I. Aslan, O. Çınar, and Ü. Özen, "Developing Strategies for the Future of Healthcare in Turkey by Benchmarking and SWOT Analysis," Procedia - Social and Behavioral Sciences, vol. 150, pp. 230-240, Sep. 2014, doi: 10.1016/j.sbspro.2014.09.043.

[9] F. Kazemi, L. Abolhassani, E. A. Rahmati, and P. Sayyad-Amin, "Strategic planning for cultivation of fruit trees and shrubs in urban 
landscapes using the SWOT method: A case study for the city of Mashhad, Iran," Land Use Policy, vol. 70, pp. 1-9, Jan. 2018, doi: 10.1016/j.landusepol.2017.10.006.

[10] S. H. Amin, J. Razmi, and G. Zhang, "Supplier selection and order allocation based on fuzzy SWOT analysis and fuzzy linear programming," Expert Systems with Applications, vol. 38, no. 1, pp. 334-342, Jan. 2011, doi: 10.1016/j.eswa.2010.06.071.

[11] O. Arslan and I. D. Er, "SWOT analysis for safer carriage of bulk liquid chemicals in tankers," Journal of Hazardous Materials, vol. 154, no. 1, pp. 901-913, Jun. 2008, doi: 10.1016/j.jhazmat.2007.10.113.

[12] J. M. Bradshaw and J. H. Boose, "Decision Analysis Techniques for Knowledge Acquisition: Combining Information and Preferences Using Aquinas and Axotl," Int. J. Man Mach. Stud., 1990, doi: 10.1016/S0020-7373(05)80044-6.

[13] D. L. Schmoldt and D. L. Peterson, "Analytical group decision making in natural resources: methodology and application," Forest Science, vol. 46, no. 1, pp. 62-75, 2000.

[14] D. W. Pickton and S. Wright, "What's swot in strategic analysis?," Strategic Change, vol. 7, no. 2, pp. 101-109, 1998, doi: 10.1002/(SICI)10991697(199803/04)7:2<101::AIDJSC332>3.0.CO;2-6.

[15] S. Ghazinoory, A. Zadeh, and A. Memariani, "Fuzzy SWOT analysis," Journal of Intelligent and Fuzzy Systems, vol. 18, pp. 99-108, Jan. 2007.

[16] T. Hill and R. Westbrook, "SWOT analysis: It's time for a product recall," Long Range Planning, vol. 30, no. 1, pp. 46-52, Feb. 1997, doi: 10.1016/S0024-6301(96)00095-7.

[17] G. Büyüközkan and O. Feyzıog̃lu, "A fuzzylogic-based decision-making approach for new product development," International Journal of Production Economics, vol. 90, no. 1, pp. 27-45, Jul. 2004, doi: 10.1016/S0925-5273(02)00330-4.

[18] M. Haile and J. Křupka, "Fuzzy Evaluation of SWOT analysis," Fuzzy hodnocení SWOT analýzy, vol. 5, no. 3, 2016, Accessed: Jul. 24, 2020. [Online]. Available: https://dk.upce.cz//handle/10195/67716

[19] M. T. Taghavifard, H. Amoozad Mahdiraji, A. M. Alibakhshi, E. K. Zavadskas, and R. Bausys, "An Extension of Fuzzy SWOT Analysis: An Application to Information
Technology," Information, vol. 9, no. 3, Art. no. 3, Mar. 2018, doi: 10.3390/info9030046.

[20] V. Vyas, A. P. Singh, and A. Srivastava, "Entropy-based fuzzy SWOT decisionmaking for condition assessment of airfield pavements," International Journal of Pavement Engineering, vol. 0, no. 0, pp. 112, Oct. 2019, doi: 10.1080/10298436.2019.1671590.

[21] A. A. Zakharova, "Fuzzy Swot Analysis for Selection of Bankruptcy Risk Factors," Applied Mechanics and Materials, vol. 379, pp. 207-213, Aug. 2013, doi: https://doi.org/10.4028/www.scientific.net/ AMM.379.207.

[22] M. Jedlickova and P. Kutnar, "Construction of a Fuzzy Model for the Success Prediction of Hi-Tech Companies With a Short History," in 17th International Scientific Conference at Brno University of Technology, Faculty of Business and Management, Brno, Czech Republic, Apr. 2019, vol. 0. Accessed: Apr. 14, 2019. [Online]. Available: https://conference.fbm.vutbr.cz/ic/index.php /ic/article/view/36

[23] A. Naba, Belajar Cepat Fuzzy Logic menggunakan Matlab. Yogyakarta: ANDI, 2009. Accessed: Jan. 14, 2019. [Online]. Available:

//pustaka.htp.ac.id/index.php?p=show_detail \&id $=4143 \&$ keywords $=$

[24] P. Melin and O. Castillo, Modelling, simulation and control of non-linear dynamical systems: An intelligent approach using soft computing and fractal theory. New Fetter Lane, London.: Taylor and Francis, 2001, p. 249.

[25] H. Hosseini-Nasab, A. Hosseini-Nasab, and A. S. Milani, "Coping with Imprecision in Strategic Planning: A Case Study Using Fuzzy SWOT Analysis," IB, vol. 03, no. 01, pp. 23-29, 2011, doi: 10.4236/ib.2011.31004. 